to the shrinking. However, when the interior afterwards cools, it undergoes great tensile stresses of contraction which can only be balanced by corresponding compression stresses on the non-yielding outside surfaces. Glass is strong in compression but weak in tension, and breaks when the critical tensile stress is developed on some part of its surface; with toughened glass this point can only be reached after first overcoming the surface compression, and as a result such glass has a breaking strength four to five times (or more, in some cases) that of glass in an ordinary annealed condition. Toughened glass is also very much more resistant to mechanical, and hence to thermal, shock; thus, it will withstand molten lead or, when hot, being sprayed with water. Because of the great strain energy stored within, toughened glass becomes reduced to small harmless granular particles on fracture, but suffers from the disadvantage that it cannot be cut, drilled, chipped, ground or otherwise worked (after toughening) without danger of such disintegration. It returns to the annealed condition at temperatures above $295^{\circ} \mathrm{C}$. The film illustrates these properties by suitable demonstrations, and then goes on to indicate the wide range of uses in commerce and industry. It is produced by Cecil Musk and runs for twenty-one minutes. Copies are available on loan from Pilkington Brothers, Ltd., Publicity Department, St. Helens, Lancs.

\section{Jenner Relics at the Wellcome Historical Medical} Museum

THE bicentenary of the birth of Edward Jenner (1749-1823) was celebrated last May, and there is still on view at the Wellcome Historical Medical Museum a collection of books, manuscripts, and other relics relating to Jenner and to his discovery of vaccination. The catalogue (obtainable only from the Oxford University Press, 2s. net) is an interesting booklet, prepared by Dr. E. Ashworth Underwood, director of the Museum. A brief account of the life and work of Jenner is followed by a description of the contents of the Exhibition. The history of smallpox and of inoculation (or variolation) has been illustrated by a series of books, and portraits of their authors, from Rhazes in the eighth century to Daniel Sutton in the eighteenth. Personal relics of Jenner include the early works on natural history which gained for him the fellowship of the Royal Society, his publications relating to vaccination, his lancets, snuff-box, spectacles, pulsometers, cupping glasses, and the medals which were struck in his honour. Perhaps the principal exhibits, and certainly the most valuable, are two manuscript copies of the famous "Inquiry", written in 1797, and now for the first time placed on view together in the central show-case. The Wellcome manuscript, though not in Jenner's handwriting, is prefaced by a letter from him, while the other manuscript, lent by the Royal College of Surgeons, is written by Jenner himself and labelled by him as "the original paper". Other exhibits deal with the progress of vaccination, the spread of the practice at home and abroad, and the adoption of glycerated calf lymph as first suggested by Robert Koch. The catalogue is an important addition to Jenneriana, and it may well form, not only an essential guide to the Museum, but also a timely tribute to one of the central figures in medical history who, it must ever be remembered, was all his life a country practitioner in a remote Gloucestershire village.

\section{Educational Films on World Resources}

The use of films for educational purposes grows, and a large number is now available. Therefore, a volume emanating from the United Nations is very welcome ("An International Index of Films on the Conservation and Utilization of Resources. Prepared by Unesco for UNSCCUR" (pp. 175; London: United Nations, 1949). The aim is to make available throughout the world material that might be useful in educational circles. There is a subject index, then an alphabetical index of titles, all in English, of some seven hundred films, and finally distribution sources and synopsis of each film. The length in minutes is given and colour or silence are noted, if necessary. There is, so far, no central library from which the films can be procured; but distribution sources are noted. While most films are available only in the language of their country of origin, some are available in English as well as a first language. Thus Danish and Dutch films can be obtained also in English, and most United Nations films in many languages.

\section{Old Stone Age in the Sudan}

A RECENT publication by A. J. Arkell, "Sudan Antiquities Service. Occasional Papers No. 1 : The Old Stone Age in the Anglo-Egyptian Sudan" (pp. $52+27$ plates; Khartoum : Commissioner for Archæology ; Cambridge: Deighton, Bell and Co., Ltd., 1949 ; 25 P.T. or $5 s$.), is of very considerable interest to students of the Old Stone Age. It consists mainly of excellent illustrations of types of palæolithic tools found in the region. The text is kept to a minimum and explains the reproductions and their geographical occurrences. There is a distribution map and a table of a possible succession of cultures in the region, with discussions of geology and climatic changes. The whole is a small but valuable scientific work.

\section{Colonial Students' Welfare in Great Britain}

ON January 1 the British Council assumed responsibility for the welfare of Colonial students in the United Kingdom, taking over a task hitherto in the hands of the Colonial Office. The Council is taking over, and will retain for the time being, the Colonial Office hostels in London, Edinburgh and Newcastle, which together accommodate about 460 in shared rooms and dormitories; but its policy is to replace or adapt them so as to provide accommodation of a standard as near as possible to that of university halls of residence. As, however, only a small proportion of the 3,500 Colonial students in the United Kingdom can be housed in such residences, the Council will make every effort to obtain for the others suitable accommodation in boarding or private houses, and staff with this special responsibility have been appointed in London and at British Council centres outside London. It has been providing a range of services to a limited number of overseas students, and these will now be extended to all Colonial students and also to students from the selfgoverning countries of the Commonwealth and from foreign countries. Though the accommodation in the residences must for the time being be reserved for Colonial students only, it is planned to develop in them social and other activities in which British students will participate. In the London area the British Council is also extending the services it has been providing for its scholarship holders and bursars 